\title{
Novel Revolution in Diagnosis and Therapy of Breast and prostate Cancer
}

\author{
Sherif Salah Hesen ${ }^{1 *}$ and Nada Sherif ${ }^{2}$ \\ ${ }^{1}$ Department of Immunology, Faculty of Veterinary Medicine, Cairo University, Cairo, Egypt \\ ${ }^{2}$ Department of Biochemistry, Faculty of Pharmacy, German University, Cairo, Egypt
}

\begin{abstract}
New cancer markers have been discovered in the form of male and female oncogene peptide protein and its anti-peptide antibodies. They were found in both salvia and blood samples of females with breast cancer and males with prostate cancer, in a pilot study for fifteen married patients having cancer in advanced-stage and their Husbands and Wives. Ten females, their age ranging from 32 to 58 for breast cancer (group A), five males for prostate cancer their age ranging from 54 to 71 years (group B), and four normal persons [two male and two female], their age ranging from 23 to 34 years] (as control group), were recruited into a controlled study to investigate the presence of the new suspected oncogene peptide proteins and their specific anti-oncogene antibodies in their blood and saliva. Tumour markers, C.T scan, ultrasound, and mammogram reports were completely collected before the study for each subject in the three groups. The collection data revealed the presence of male oncogene peptide protein [MOP] in serum and saliva samples of male Husbands in group $A$ and its specific anti-oncogene antibodies [AMOP] in the serum samples of each female affected with breast cancer in group $A$, and the presence of female oncogene peptide protein [FOP] in all five female Wives and its specific anti-oncogene antibodies [AFOP] in each male affected with prostate cancer in group $\mathrm{B}$, and the differences between normal controls and cancer patients were estimated by different in vitro and in vivo experimental trails. Our conclusions showed that a direct relation exists between the increases in concentration levels of OPP and its AOAbs, and the stage of malignancy. These promising results can open the doors for a new challenge, by developing a therapeutic and prophylactic cancer vaccine as well as new biological markers for breast and prostate cancer.
\end{abstract}

Keywords: Immunodiapostics; Oncogene peptides; Immunization; Monoclonal antibody; Breast cancer; Prostate cancer; Oncogene peptide protein; Anti-oncogene antibodies; Husbands group A; Wives group B

\section{Introduction}

Psychological stress describes what people feel when they are under mental, physical, or emotional pressure. It is possible that psychological stress acts as an inducer for cancer growth. But, although stress can cause a number of physical health problems $[1,2]$, the evidence that it can cause cancer is weak. Some studies have indicated a link between various psychological factors and an increased risk of developing cancer, while others have not [3]. Breast cancer is the second most common malignancy in women and the second leading cause of death. Breast cancer is three times more common than all gynaecological malignancies put together. The incidence of breast cancer has been increasing steadily from an incidence of 1:20 women in 1960 to 1:8 women today. Breast cancer is not exclusively a disease of women $[4,5]$. Breast cancers can start from different parts of the breast [6].

Prostate cancer is the most common cancer in men in the United States, after skin cancer. It is the second leading cause of death from cancer in men. Prostate cancer occurs more often in African-American men than in white men [7]. African-American men with prostate cancer are more likely to die from the disease than white men with prostate cancer. The research on cancer and its causatives is still one of the most important research topics, proceeding from contrasting medical, analytical and philosophical views in interpreting the phenomenon of cell carcinogenesis. The most salient of these views that we discuss in this research today is the relation resulting from the cellular transmission and reception, which assures that every one of us bears receptive readiness to a certain inducer. The existence of this inducer will initiate the cancer presence. Some types of cancer such as liver cancer are related to the presence of a viral inducer, as result of exposure to which the liver is affected with epidemic liver virus " $\mathrm{C}$ " or "B", and it is one of the relations that interprets the transmission and receiving phenomenon. The virus is found in millions of patients infected by hepatitis HBV, but the likelihood of appearance of cancer patients from these numbers is very low, at $9.4 \%$. The reason behind this refers to the presence of an inducer in the virus's genetic composition, which receives these signals in a conscious state and is able to understand the nature of it to a point at which the gene stimulation process is initiated inside the liver cell, in other words the readiness to receive such signals is what determines who has the ability to deal with it; there is an indicative relation that has its own language.

But we share here that while the presence of the virus inside the cellular composition no doubt has a negative impact on the cell, we believe that the signals that cause stress on the cell and take it in a direction which opposes its natural function, form the core of the cell mutation. Therefore, every action or production made by any cell inside the whole cellular set is only a transmission of signals understood by every cell according to the nature of its outer coat, so that it starts producing anti-reactions. Which is nothing but protein residues related to the production nature of the same cell? Our eye retina has complete consciousness of light and its nature, speed and intensity, which gives

*Corresponding author: Sherif Salah Hesen, Department of Immunology, Faculty of Veterinary Medicine, Cairo University, Cairo, Egypt, Tel: +20235676105; E-mail sherif64@usa.com

Received March 22, 2018; Accepted May 07, 2018; Published May 09, 2018

Citation: Hesen SS, Sherif N (2018) Novel Revolution in Diagnosis and Therapy of Breast and prostate Cancer. J Cancer Sci Ther 10: 110-117. doi: 10.4172/1948-5956.1000527

Copyright: $\odot 2018$ Hesen SS, et al. This is an open-access article distributed unde the terms of the Creative Commons Attribution License, which permits unrestricted use, distribution, and reproduction in any medium, provided the original author and source are credited. 
it the ability to receive light signals, and it contains cellular devices that translate these light messages and convert them into electro-chemical messages understandable to the brain, like the sensitive auditory cells that convert audio frequencies into electro-chemical relations that get grasped in the brain in protein matter and are stored to be able to recall them one more time. We store all external awareness in the form of protein receptors. Despite the changes in transmitted signals, everyone can store all his relationships with other beings through protein receptors found inside him, that he uses to revive the conscious centre with all beings previously dealt with. So these protein receptors will represent the language of the direct push of the nerves' movement, and then the organs and muscles [8].

The cancer that affects males and females is only an actual translation supporting this concept. The female has an organ prepared to receive the feminine conscious through the consciousness originally inherent inside the cell, which relates between the received signal and that found in its genetic code, which can interpret every signal as it is and it is the same with the male. There is no contradiction in mentioning that the masculine and feminine factors when received, it is supposed to happen in its natural form, but it is possible that the male and female can refuse their feeling towards each other, due to the display of other genetic inducers which resist the appearance of those normal factors. Not only this, but the male may be obliged to make hormonal secretion from his exposure to signals from the female against his original male centres. Through the continuous negative genetic factor thrusts, this will be a serious indicator of another genetic activity related to these masculine or feminine genes and begin its work as soon as the inducer is found. In our study, we found that male and female anti-oncogene peptide as a fingerprint in the blood is able to receive the inducer at the moment it increases or exists in the blood. Therefore, through this, we may be able to extract the mating relation among male or female cancerous inducers and their antagonists that in result will excite cellular activity in the male and female organs.

The female feminine organ works due to the existence of feminine hormones represented in oestrogen, progesterone. These feminine hormones play the main role in the cellular activity of the breast and also the uterus cellules, preparing it for the operations of oviparity, pregnancy and sexual sensation. The first hormones of the female represent the most salient feminine hormones that come out of the ovary following the induction of FSH and LH hormones by the pituitary gland. The Same applies to the male, which is prepared for sexual sensation and practice of this sensation by the brain centres which translate the sonic photic and sensory messages so that the brain will be excited, then signals are sent to the pituitary glands to secrete FSH and LH hormones which induce the testicles to excrete the male hormone, which is the "testosterone", to be received by the prostate representing the male sexual adaptation gland, exactly as the breast is in the female [9].

The appearance of the disorder in the natural context of this physiologic set is by chemical signs of a contrary language source that acts in the same way and in a contrary direction at the same time. That is, the refusal of the male or female to the relation between each other results in the brain issuing a decision to change the signal issued to each of them, to a signal that the brain on its base releases inducers that hinder the work of the sexual sensation cells. The female receives the sensation from the male either by the sonic or visual signs, which are changed by the sensitive neural cells to a determined language sent to the brain.
And according to the effect of this image or voice, in affecting a gene in the brain cells, related to the signal nature, it will produce a female oncogene, that is related to inducing the pituitary gland to excrete hormones that are prepared for the feminine activity that will be directed towards the breast where it is going to be received on the surface of the breast cells to stop their sensation readiness, and to induce the cellule to produce a new protein addressing another gene inside the cellule that excites the cellule to proliferation in a cancerous direction, or where the sensation takes off from the sexual organic sensation cellules as in the breast, to send a sign to the cerebrum with the nature and type of its genitor whereas this sign represents to the cerebrum a contrary response, and this antigen takes off the breast cellules to control the receptive reaction, and thereby induces the cancerous factors. As it happens to the male, so does it happen to the female?

\section{Experimental Procedure}

Volunteers enrolled in this work consisted of fifteen married patients having cancer at an advanced-stage and their husbands and wives. Ten females, their age ranging from 32 to 58 for breast cancer (group A), five males for prostate cancer with age ranging from 54 to 71 years (group B) and four normal persons [two male and two female], their age ranging from 23 to 34 years (as control group) were recruited into a controlled study to investigate the presence of new suspected OPP and its AOPAs in their blood and saliva. Laboratory screening markers, C.T scan ultrasound, and mammogram reports $[10,11]$ were completely collected before the study for each subject in the three groups and is shown in Tables 1 and 2.

\begin{tabular}{|c|c|c|c|c|c|}
\hline \multicolumn{2}{|c|}{ Patients } & \multicolumn{3}{c|}{ Mammogram results } & \multicolumn{2}{c|}{$\begin{array}{c}\text { Laboratory tumour } \\
\text { marker results }\end{array}$} \\
\hline No. & Age & Mass size & Axillary L. N & CA 27-29 & CEA \\
\hline $\mathrm{F}_{1}$ & $32 \mathrm{y}$ & $0.7 \mathrm{~cm}$ & $+\mathrm{ve}$ & $74 \mathrm{u} / \mathrm{ml}$ & $34 \mathrm{ng} / \mathrm{ml}$ \\
\hline $\mathrm{F}_{2}$ & $41 \mathrm{y}$ & $1.5 \mathrm{~cm}$ & $+\mathrm{ve}$ & $93 \mathrm{u} / \mathrm{ml}$ & $55 \mathrm{ng} / \mathrm{ml}$ \\
\hline $\mathrm{F}_{3}$ & $43 \mathrm{y}$ & $1.0 \mathrm{~cm}$ & $+\mathrm{ve}$ & $66 \mathrm{u} / \mathrm{ml}$ & $47 \mathrm{ng} / \mathrm{ml}$ \\
\hline $\mathrm{F}_{4}$ & $49 \mathrm{y}$ & $2.5 \mathrm{~cm}$ & $+\mathrm{ve}$ & $102 \mathrm{u} / \mathrm{ml}$ & $89 \mathrm{ng} / \mathrm{ml}$ \\
\hline $\mathrm{F}_{5}$ & $55 \mathrm{y}$ & $3.2 \mathrm{~cm}$ & $+\mathrm{ve}$ & $178 \mathrm{u} / \mathrm{ml}$ & $121 \mathrm{ng} / \mathrm{ml}$ \\
\hline $\mathrm{F}_{6}$ & $58 \mathrm{y}$ & $3.5 \mathrm{~cm}$ & $+\mathrm{ve}$ & $128 \mathrm{u} / \mathrm{ml}$ & $56 \mathrm{ng} / \mathrm{ml}$ \\
\hline $\mathrm{F}_{7}$ & $55 \mathrm{y}$ & $4.0 \mathrm{~cm}$ & $+\mathrm{ve}$ & $90 \mathrm{u} / \mathrm{ml}$ & $67 \mathrm{ng} / \mathrm{ml}$ \\
\hline $\mathrm{F}_{8}$ & $54 \mathrm{y}$ & $2.5 \mathrm{~cm}$ & $+\mathrm{ve}$ & $85 \mathrm{u} / \mathrm{ml}$ & $120 \mathrm{ng} / \mathrm{ml}$ \\
\hline $\mathrm{F}_{9}$ & $51 \mathrm{y}$ & $3.0 \mathrm{~cm}$ & $+\mathrm{ve}$ & $39 \mathrm{u} / \mathrm{ml}$ & $67 \mathrm{ng} / \mathrm{ml}$ \\
\hline $\mathrm{F}_{10}$ & $57 \mathrm{y}$ & $1.5 \mathrm{~cm}$ & $+\mathrm{ve}$ & $77 \mathrm{u} / \mathrm{ml}$ & $190 \mathrm{ng} / \mathrm{ml}$ \\
\hline
\end{tabular}

NB: Normal values [CA $27-29$ up to $38 \mathrm{u} / \mathrm{ml}$ ] [CEA up to $2.5 \mathrm{ng} / \mathrm{ml}$ ]

Table 1: Describes all females of the first group and their results with mammogram and laboratory screening tests (represented as Fe1 to Fe 10), where this table describes the age of each female, the results of tumour marker investigation and their breast mass size shown by mammogram.

\begin{tabular}{|c|c|c|c|}
\hline \multirow{2}{*}{ Patients } & \multirow{2}{*}{ Age } & \multicolumn{2}{|c|}{ Laboratory test results } \\
\cline { 2 - 4 } & & PSA & PAP \\
\hline M 1 & 54 & $10.5 \mathrm{ng} / \mathrm{ml}$ & $62 \mathrm{ng} / \mathrm{ml}$ \\
\hline M2 & 58 & $17.0 \mathrm{ng} / \mathrm{ml}$ & $105 \mathrm{ng} / \mathrm{ml}$ \\
\hline M 3 & 64 & $18.3 \mathrm{ng} / \mathrm{ml}$ & $101 \mathrm{ng} / \mathrm{ml}$ \\
\hline M 4 & 69 & $28.0 \mathrm{ng} / \mathrm{ml}$ & $121 \mathrm{ng} / \mathrm{ml}$ \\
\hline M 5 & 71 & $12.1 \mathrm{ng} / \mathrm{ml}$ & $220 \mathrm{ng} / \mathrm{ml}$ \\
\hline \multicolumn{2}{|l}{ NB: Normal values [PSA: $0-4 \mathrm{ng} / \mathrm{ml}],[$ PAP: $0-2.7 \mathrm{ng} / \mathrm{ml}]$} \\
\hline
\end{tabular}

Table 2: Describes all the males affected by prostate cancer in group $B$ which are represented as (Ma1 to Ma 5), where this table shows the age of each male participant in this trial, the results of both laboratory screening test PSA, PAP which showed increased in their level above the normal value. 


\section{Blood sampling}

$30 \mathrm{cc}$ of blood was withdrawn and collected from all groups, and the quantity of blood was divided as follows: $25 \mathrm{~cm}$ with EDTA and 5 $\mathrm{cm}$ without anticoagulant. The clotted blood samples were collected in clean containers and centrifuged at $2500 \mathrm{~g}$ for 30 minutes to separate serum which was then pooled and kept at $-40^{\circ} \mathrm{C}$. The whole blood components were separated from the anticoagulant samples and kept at $-65^{\circ} \mathrm{C}$.

\section{Saliva samples preparation}

$10 \mathrm{ml}$ of saliva was collected for all groups, and each sample was diluted with $0.5 \mathrm{ml}$ phosphate buffer saline, $\mathrm{pH}$ 7.2. The mixture was moved to refrigerator at $4^{\circ} \mathrm{C}$ for $2 \mathrm{hrs}$. Then it was centrifuged at $1000 \mathrm{~g}$ for 10 minutes to separate supernatant and diluted with distilled water as follows $(1 / 10,1 / 20,1 / 40,1 / 80)$.

\section{RBCs agglutination reaction}

$2 \mathrm{ml}$ of anti-coagulant blood was obtained from females affected with breast cancer in group $\mathrm{A}$ and males affected with prostate cancer in group B for separation of red blood cells, and the collected cells were washed three times by salt solution $0.9 \mathrm{gm} / \mathrm{L}$ to ensure elimination of all other proteins impurities. We poured the supernatant to collect the RBCs sediment, and then we added $100 \mu$ of RBCs of the blood sample for the females affected with breast cancer in group A to $100 \mu$ of isolated saliva peptide from male Husbands in group A in clean glass slides and we examined them for the agglutination of RBCs together. We also matched $100 \mu$ of isolated saliva peptide from female Wives in group B to $100 \mu$ of RBCs of the blood sample for the males affected with prostate cancer in group $\mathrm{B}$. The agglutination formation for RBCs of females affected with breast cancer in group A and males affected with prostate cancer in group B with the saliva samples obtained from male Husbands in group A and female Wives in group B were recorded to evaluate the presence of relation between every couple separately, and the presence of this agglutination if we examined them randomly with each other.

\section{Investigate the relation between each couple of group A and B}

$5 \mathrm{cc}$ of blood sample without anticoagulant was collected in clean containers and centrifuged at $2500 \mathrm{~g}$ for 10 minutes to separate serum for females affected with breast cancer and their Husbands in group A, males affected with prostate cancer and their wives in group B, which was then pooled and kept at $-4^{\circ} \mathrm{C}$. Using HiPer ${ }^{\circledR}$ Ouchterlony four Diffusion Teaching Kit [12,13]. (Antigen- Antibody Pattern), we started matching every serum and saliva sample of every Husband in group A versus the serum samples of four females in the same group and continuously in the same manner by testing every Husband's serum and saliva versus every female in group A [14]. We added $30 \mu$ each of Husband serum and the corresponding four female serum in the same group to the wells [HA1 serum versus Fe A1, Fe A2, Fe A3, Fe A4 serum where $\mathrm{H} A$ is every Husband in group $\mathrm{A}$ and $\mathrm{Fe} \mathrm{A}$ is every female affected with breast cancer in group A], and in the same manner we did this procedure for all testes of husbands versus their affected wives in Group A. We also tested the serum samples of the Wives in group B versus their Husbands in the same group [W1 serum versus Ma B1, Ma $\mathrm{B} 2$, Ma B3, Ma B4 serum where $\mathrm{W}$ is the every wife in group $\mathrm{B}$ and $\mathrm{Ma}$ is the every male affected with prostate cancer in group B], in the same manner as previously explained, then we kept the glass plate in a moist chamber overnight at $37^{\circ} \mathrm{C}$ as shown in Figure 1.

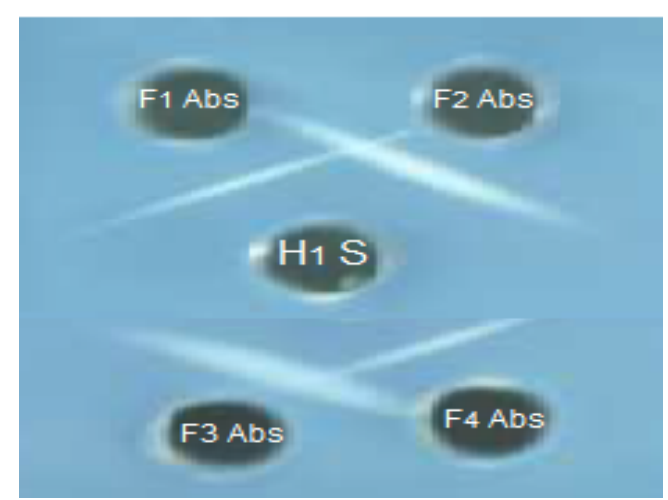

Figure 1: In Ouchterlony four diffusion (Antigen antibody pattern), when the specific antigen in serum sample of male Husband in group A meets the specific antibodies in serum samples of female patients in group A, precipitation line is formed between antigen and antisera, which indicates that the antigens are immunologically identical.

Purification of unknown oncogene peptide protein and its antioncogene antibodies with ammonium sulphate

$10 \mathrm{cc}$ of serum samples were obtained from each female affected with breast cancer and their male Husbands in group A, males affected with prostate cancer and their male Wives in group B, to isolate the unknown oncogene peptide protein and anti-oncogene antibodies in their serum samples. Saturated ammonium sulphate (SAS) was prepared as Working solution of $80 \%$ ammonium sulphate solution. First step of precipitation using ammonium sulphate aimed to remove large sized proteins and albumin. Serum samples were diluted 3-fold with phosphate buffer saline, $\mathrm{pH} 7.2$, then 0.5 volume of saturated ammonium sulphate solution (4.1 M solution $\mathrm{pH}$ 7-7.2) was added slowly with constant stirring for 30 minutes. The mixture was kept at $4^{\circ} \mathrm{C}$ overnight, then centrifuged at $1000 \mathrm{~g}$ for 30 minutes and pellet was discarded since it contained undesired large MW proteins. Supernatant was then collected and its amount was measured, and another 0.5 volume of saturated ammonium sulphate solution was added slowly with constant stirring. The mixture was moved to refrigerator at $4^{\circ} \mathrm{C}$ overnight then centrifuged at $1000 \mathrm{~g}$ for 30 minutes to separate pellet from supernatant. The first precipitation step was successful in removing large molecular weight protein aggregates and any proteins that may precipitate with low concentrations of ammonium sulphate. This first precipitation was termed ( $\operatorname{Pr} 1$ the First precipitate containing oncogene peptide). The purified sediments were added to $1.5 \mathrm{ml}$ of 0.9 $\mathrm{NaCl} 0,09 \%$, and $\mathrm{NaN} 3$ was added as preservative and the mixture was capped and stored to be ready for isolating the unknown peptides. After the second precipitation step the final concentration of ammonium sulphate reached $50 \%$, which was quite enough to precipitate IgG. The purified IgG of every affected female and male in group A and B was diluted with $1.5 \mathrm{ml}$ of $0.9 \mathrm{NaCl} 0,09 \%, \mathrm{NaN} 3$ as preservative was added, and this precipitated IgG was termed (Pr 2 the Second precipitate containing IgG Abs).

Characterization of oncogene peptide protein and its antioncogene-antibodies

We used Magne HaloTag Beads (Promega) - Magne HaloTag Beads are magnetic cellulose beads activated with HaloTag - and embedded them in $1.5 \mathrm{ml}$ mixtures of $(\operatorname{Pr} 2)$ solution which contains the suspected unknown anti-oncogene antibodies of each female affected with breast cancer in group A and incubated them at room temperature for $2 \mathrm{hrs}$. 
Citation: Hesen SS, Sherif N (2018) Novel Revolution in Diagnosis and Therapy of Breast and prostate Cancer. J Cancer Sci Ther 10: 110-117. doi: 10.4172/1948-5956.1000527

Then we washed it several times to remove the unbound antibodies, samples with magnetic beads were placed in the magnetic stand, and then we transferred it to the second mixture ( $\operatorname{Pr} 1)$ which contains the suspected unknown oncogene peptide protein in male Husbands of group A. Using the same procedure we put Halo magnetic beads in 1.5 ml mixtures of $(\operatorname{Pr} 2)$ solution which contains the suspected unknown anti-oncogene antibodies of each male affected with prostate cancer in group A and incubated them at room temperature for $2 \mathrm{hrs}$. Then we washed it several times to remove the unbound antibodies, samples with magnetic beads were placed in the magnetic stand, then we transferred it to the second mixture ( $\operatorname{Pr} 1)$ which contains the suspected unknown oncogene peptide protein in female Wives of group B and incubated them for $2 \mathrm{hrs}$. At room temperature to allow the antibodies captured in the surface of Magne Halo Tag Beads to catch the peptides. Then we washed the beads to discard the unbound complex formation (three times with $200 \mu \mathrm{l}$ of PBS), bead bound-antibody was eluted twice with $50 \mu$ lof elution buffer ( $10 \mathrm{mM}$ glycine- $\mathrm{HCl}$ buffer, $\mathrm{pH}$ 2.2-2.7) and immediately neutralized with $10 \mu \mathrm{l}$ of neutralization buffer $(2 \mathrm{M}$ Tris buffer, $\mathrm{pH}$ 7.5), the complex bound antigen and antibodies obtained were diluted with $2 \mathrm{ml}$ of PBS, and centrifuged at $3000 \mathrm{rpm}$ for $30 \mathrm{~min}$ at room temperature. The supernatants were removed again and diluted with $2 \mathrm{ml}$ of PBS and stored in clean tubes in regenerator at $-4^{\circ} \mathrm{C}$ as male and female oncogene peptide protein (FOP, MOP). The sediment collected at this time mainly contains the suspected anti-oncogene antibodies (AMOP, AFOP). Then we added $2 \mathrm{ml}$ of PBS solution to this sediment and stored it under $-4^{\circ} \mathrm{C}$ as anti-oncogene antibodies. By this process, we obtained the unknown oncogene peptides from every serum and saliva of male Husbands and female Wives in both groups and the unknown anti-oncogene antibodies from every female affected with breast cancer and male affected with prostate cancer in groups $\mathrm{A}$ and B.

\section{Identification of the antigen and antibody reaction in both groups}

For each purified isolated unknown antibodies $(\operatorname{Pr} 2)$ sample from male and female in group A, B that was affected with cancer and for the control group, a serial dilution using PBS was used as follows $(1 / 10$, $1 / 20,1 / 40,1 / 80)$ as $\mathrm{T} 1$, then the obtained four dilutions of unknown antibodies were stored at $-20^{\circ} \mathrm{C}$ to be ready for use. Also, for the purified ( $\operatorname{Pr} 1)$ isolated unknown oncogene peptide protein of the male Husbands in group A and female Wives in group B, a serial dilution using PBS was used as follows $(1 / 10,1 / 20,1 / 40,1 / 80)$ as T2, then the obtained four dilutions were stored at $-20^{\circ} \mathrm{C}$ to be ready for use.

The experiment was designed as follows: Each dilution of T1 antiFemale oncogene antibodies $(1 / 10,1 / 20,1 / 40,1 / 80)$ of each female affected with breast cancer in group A matched the different dilutions of T2-Male oncogene peptide $(1 / 10,1 / 20,1 / 40,1 / 80)$ of every male Husband in the same group, and in the same manner, each dilution of T1-anti-Male oncogene antibodies $(1 / 10,1 / 20,1 / 40,1 / 80)$ of each male affected with prostate cancer in group $\mathrm{B}$ matched the different dilutions of T2-Female oncogene peptide $(1 / 10,1 / 20,1 / 40,1 / 80)$ of each female wife in the same group. Also, we matched the isolated oncogene peptides of male Husbands in group A and Wives of group B versus the control diluted serum samples. In the next step, we used -30 $\times 96$ Corning Costar well stripwell plate and designed it for this trail as follows; we added $100 \mu \mathrm{g} / \mathrm{ml}$ from $\mathrm{T} 1$ as first dilution of every female in group A into the appropriate wells and by the same sequence from 2, 3 and 4 dilutions, another group of plates was used for each male affected for prostate cancer in group B into the appropriate wells. In this way, we coated another group of wells with $100 \mu \mathrm{g} / \mathrm{ml}$ from $\mathrm{T} 1$ as first dilution of every male in group B wells and by the same sequence from each 2, 3 and 4 dilution, the designed coated wells that contained antiMOP and anti-FOP were nominated to match only the T2 dilutions of each male Husband or female Wife of their specific. The designed wells for matching process for group A and B and control group are shown clearly in Figures 2-5.

All the coated plates were incubated at room temperature for 24 hrs. At $4^{\circ} \mathrm{C}$. We flooded each well of the plate with wash buffer and flicked out the liquid, and we repeated this, washing the plate 3 times and patting dry on a paper towel.

$100 \mu \mathrm{g} / \mathrm{ml}$ of each T2 dilution for the first male Husband was added to the appropriate wells, then we incubated them for 1 hour and after that we poured the solution and washed the plate with $200 \mu \mathrm{l}$ per well wash buffer for 3 minutes on a shaking platform, $100 \mu$ of anti-human

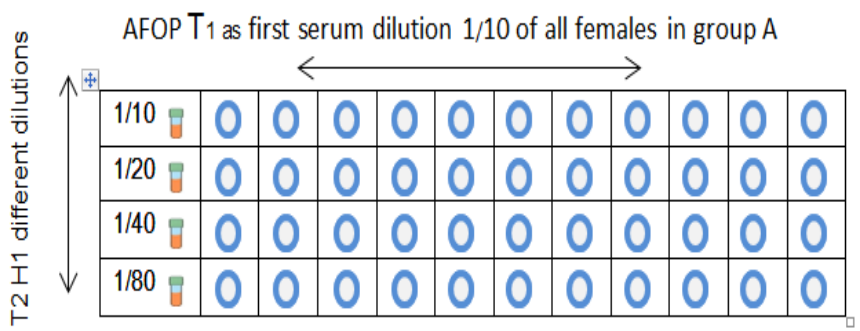

Figure 2: Describes the matching process between $T_{2}$ as female oncogene peptide suspected to be found in all male Husbands of group A versus $T_{1}$ dilution of anti-Female oncogene antibodies in all females affected with breast cancer in group $\mathrm{A}$, where $\mathrm{H}_{1}$ was the Husband no.1 and where AFOP are the anti-Female oncogene peptides of all females affected.

AMOP $T_{1}$ as first serum dilution $1 / 10$ of all males in group $B$

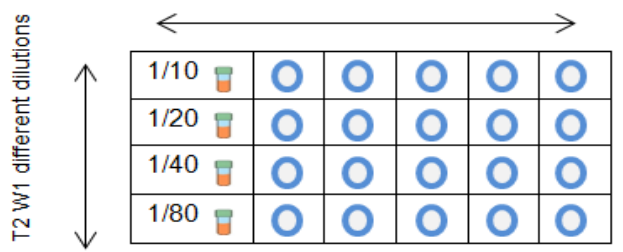

Figure 3: Describes the matching process between $T_{2}$ as female oncogene peptide suspected to be found in all female wives of group $B$ versus $T_{1}$ dilution of anti-Female oncogene antibodies in all males affected with prostate cancer in group $B$, where $W_{1}$ is the wife no.1 and AMOP are the anti-male oncogene peptides of all males affected with prostate cancer in group $B$.

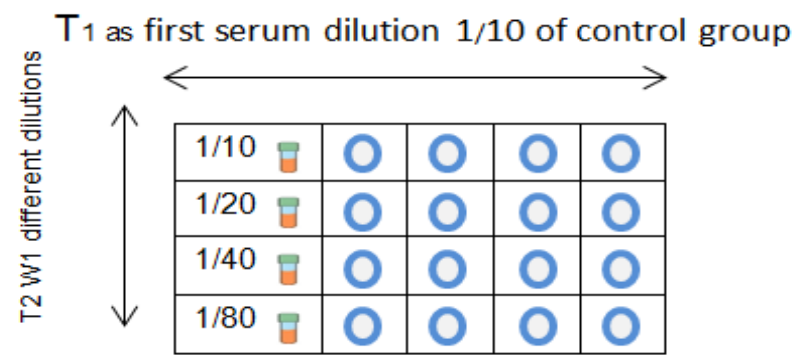

Figure 4: Describes the matching process between $T_{2}$ as female oncogene peptide suspected to be found in all female Wives of group $B$ versus $T_{1}$ dilution of first male in control group. 


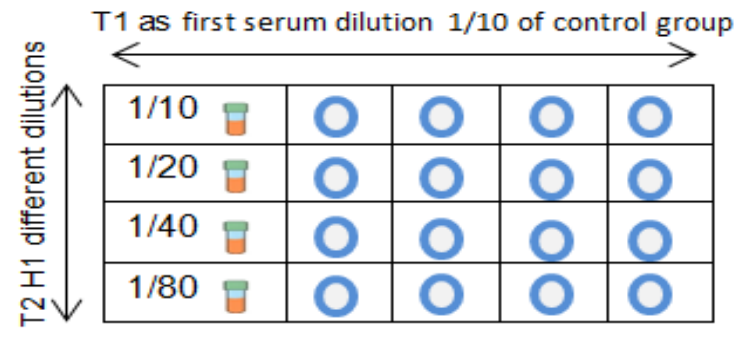

Figure 5: Describes the matching process between T2 as male oncogene peptide suspected to be found in all male Husbands of group A versus T1 dilution of first female in control group.

IgG enzyme conjugate was added. After incubating for 1 hour at room temperature, we removed the solution and washed the plate with $200 \mu \mathrm{l}$ per well wash buffer for 3 minutes on a shaking platform, and then we added TMB substrate solution to the plate before incubating the plate at RT until the desired colour intensity was reached. We stopped the reaction by adding an equal amount of stop solution, and we measured the absorbance of the colour with ELISA plate reader at $450 \mathrm{~nm}$.

Explore the effect of anti-FOP and MOP antibodies in inducing immune protection in laboratory animals

Female and males 6-8-week old mice were prepared for immunization with different dilutions of (AMOP and AFOP) $(1 / 10$, $1 / 20,1 / 40,1 / 80$ ). Male mice were injected for 8 days with $0.1 \mathrm{ml} \mathrm{S.C.}$ two times daily with AMOP as antibodies collected from females affected with breast cancer in group $\mathrm{A}$, whereas the female mice were injected with AFOP as antibodies collected from males affected with prostate cancer in group B. The injections were done for male and female mice nearly at the anterior belly, while the control group female and male mice were not immunized with AMOP or AFOP. Then on day 9 , the male mice were challenged to injected with $0.02 \mathrm{ml}$ of MOP near the neck area at 12 am and at 8 pm for 10 days, while the immunized female mice were injected with $0.02 \mathrm{ml}$ of FAP near the neck area at 12 am and at $8 \mathrm{pm}$ for 10 days, and the control mice group was injected in the same manner for FOP and MOP, then we checked all male and female mice for success or immunization failure.

Investigate the effect of MOP and FOP in induction of tumour activity. Immunizing antigens preparation

$2 \mathrm{ml}$ of Serum, $2 \mathrm{ml}$ of saliva of male Husbands and females affected with breast cancer in group $A$, males affected with prostate cancer and their females Wives in group B, every $1 \mathrm{ml}$ of saliva and serum sample were diluted with $2.5 \mathrm{ml}$ phosphate-buffered saline (PBS) and $1 \mathrm{ml}$ of Freund's adjuvant (IFA) respectively, the mixture was ready to be injected, and expressed for both couples in group A and B as follows: FAS as every female serum mixture affected with breast cancer in group A , HAS as every Husband serum mixture in group A, FAv as each female saliva mixture sample in group A and HAv as the saliva mixture of each male Husband in group A; whereas the samples of group B were expressed as MBS as each male serum mixture affected with prostate cancer in group B, WBS as each Wife serum sample mixture in group $\mathrm{B}, \mathrm{WBv}$ as each female saliva mixture sample and $\mathrm{MBv}$ as the saliva mixture of each male in group $\mathrm{B}$. Female and male 6-8-week old mice were obtained for this study. The procedure of immunization was designed as follows; the female mice were injected with $0.1 \mathrm{ml}$ S.C. of FAs, HAs, FASv, HASv and WB, MBs, WBSv, as male and female serum and saliva samples. We injected each type as far as at the nape of the neck for 17 days, the male mice were injected in the same manner with both group A and B for the same duration and in the same concentrations. Each group was examined separately for the effect of the oncogene peptide in the serum and saliva in inducing tumour growth in mice.

Preparation of isolated peptide and antibodies as marker strips for diagnosis of breast cancer and prostate cancer

We prepared two sample strips either for detection of anti-male oncogene peptide in male suspected for prostate cancer and anti-female oncogene peptide in female suspected for cancer of breast. The strip test utilizes the principle of immunochromatography and is a unique twosite immunoassay on a membrane. Both of the previously isolated MOP and FOP were conjugated with colloidal gold as the detector reagent, and every peptide was immobilized on the nitrocellulose membrane as the capture reagent. As the test serum sample $(100 \mu \mathrm{l})$ of a suspected male or female with prostate or breast cancer flows through the membrane assembly of the device, the antigen-colloidal gold conjugate complexes with anti-MOP or with anti-FOP antibodies in the sample. This complex moves through the membrane to the test region, where it is immobilized by the peptide coating of the membrane, leading to formation of a clear red-purple coloured band which confirms a positive test result. The absence of this coloured band in the test region indicates a negative result. The unreacted conjugate and unbound complex move further on the membrane and are subsequently immobilized by anti-MOP or anti-FOP antibodies on the membrane at the control region, forming a red-purple band. The manufactured prototype model as a novel screening assay for detection of prostate and breast cancer was ready to be tested to detect unknown patients and known patients previously diagnosed with breast and prostate cancer. 22 subjects were nominated for this trial, 15 subjects were females and males affected with breast and prostate cancer respectively, and 7 subjects, 4 of them female, had a family history for breast cancer and the other three subjects were male having early signs of prostatitis and their PSA ranged from 4-9 ng/ml.

\section{Results}

The outcomes result for the first experiment showed that the RBCs collected from the females affected with breast cancer in group A could agglutinate each other when we added to it $100 \mu$ saliva of their male Husbands as shown in (Figure 6). Also, the RBCs obtained from males affected with prostate cancer in group B could agglutinate each other when we added $100 \mu$ saliva of their female wives but the obtained RBCs from male and female control group could not agglutinate each other when we added $100 \mu$ saliva of male Husbands and female Wives. The

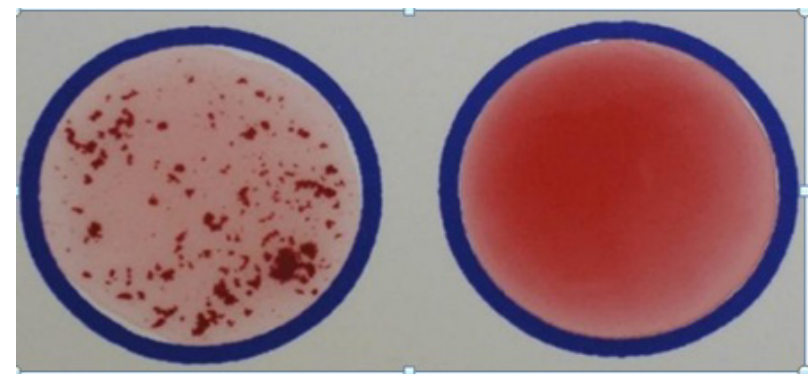

Figure 6: Describes the agglutination formation for RBCs of females affected with breast cancer in group $A$ and males affected with prostate cancer in group $B$ with the saliva samples obtained from male Husbands in group $A$ and female wives in group $B$ in left circle, while the non-reaction is described in the right-hand side circle which showed no agglutination formation. 
results confirmed that female Wives in group B had oncogene peptide protein in their saliva and the male Husband of group A had female oncogene peptide protein in their saliva.

In investigation if there is a relation between every male married to a female affected with breast cancer and every female married to a male affected with prostate cancer or not in experiment 2 revelled after incubation formation of opaque precipitin lines between the antigen suspected in serum and saliva of male Husbands and its specific antibodies in serum samples of females in group A as well as the formation of opaque precipitin lines between the antigen suspected in serum and saliva of female Wives and its specific antibodies in serum samples of males in group B wells. However, testing serum and saliva samples of control group versus the serum and saliva samples of females affected with breast cancer or males affected with prostate cancer did not show any precipitin line formation.

Identify the relation between the females affected with breast cancer and their Husbands who were not affected before with any cancer as explained from their documents pre-study, by measuring the intensity of blue colour developed by ELISA plate reader, where we recorded different readings for each male Husband and female Wife in both groups. In matching the different dilutions of T2 as female oncogene peptide versus $\mathrm{T} 2$ dilution of anti-female oncogene antibodies in all females affected for breast cancer in group A for the first male Husband in the same group, the intensity of blue colour in examined coated wells starts to grow in the first two dilutions of $\mathrm{T} 1$ in all females affected with breast cancer. Four females showed growing of the blue colour with dilution 1/40 T1, and only two females showed this blue colour growing in all dilutions of T1. In male Husband no. 2 the matching process for the $\mathrm{T} 1$ dilution of anti-female oncogene antibodies first dilution for all females of group A versus the different T2 dilutions for the second male Husband in the same group, the intensity of blue colour in examined coated well starts to grow in the first dilution of $\mathrm{T} 1 \mathrm{in}$ all females affected with breast cancer. Six females showed growing of the blue colour with dilution $1 / 20$, three females with $1 / 40 \mathrm{~T} 1$ and only two females showed this blue colour growing with all dilutions of $\mathrm{T} 1$. When we were matching the $\mathrm{T} 1$ dilution of each male affected for prostate cancer in group $\mathrm{B}$ versus the different dilutions of $\mathrm{T} 2$ for the first female Wives in the same group, the intensity of blue colour in examined coated well starts to grow in the first two dilutions of T1 dilution of anti-Male oncogene peptide in all males affected for prostate cancer, and only one male showed this blue colour growing with $1 / 40$ of T1 dilution. While comparing these results to the results of matching every $\mathrm{T} 2$ dilution of group A and T2 dilution of group B to different T1 dilutions of control group, the matching operation didn't show any remarkable growing of the blue colour in all examined coated wells of T1 dilution. These results which were obtained for all females affected for breast cancer and males for prostate cancer revealed that the male oncogene peptide protein was found in all female Wives of group B and can be bound to its purified T1 anti-male oncogene peptide antibodies of males affected with prostate cancer in group B. Also, the male oncogene peptide protein was found in all male Husbands of group A and can be T1 anti-female oncogene peptide antibodies of females affected with breast cancer in group B. As an insight into these results of matching process in all Husbands and Wives, still the most common factor among them is the formation of deep blue colour in examined wells with the first T1 dilution of group $\mathrm{A}$ and $\mathrm{T} 1$ dilution of group $\mathrm{B}$, which denotes the importance of dilution concentrations in designing an accurate screen test (Figures 7 and 8 show the matching process in group A and B).
Immunization of female mice with different dilutions of $(1 / 10$, $1 / 20,1 / 40,1 / 80$ ) with anti-MOP for 8 days and then injecting the MOP as a potential tumour oncogene for another 10 days, the female mice which were immunized with the first and second dilutions generated an effective immune response and complete rejection of tumour growth by switching the potential role of MOP in enhancement of tumour growth in comparison to the control group which were not immunized with anti-MOP. The other female mice which were immunized before peptide injection with the $1 / 40,1 / 80$ dilutions of anti-MOP showed growth of tumour activity and changes in their weight and appetite for all female mice, while the male mice which were immunized for the first three dilutions of anti-FOP for 8 days pre-injection of FOP for another 10 days did not show any marked signs of tumour growth and all the mice showed hyper-physical activities in comparison to the control group male mice, which showed growth of tumour activity for all of them. The results obtained give us a will know about the role of anti-MOP in switching off the potential effect of MOP as stimulant of tumour growth and the role of antibodies concentrations as antagonists for the oncogene peptides and reveal great possibilities for developing a prophylactic and therapeutic vaccine for prostate and breast cancer (Figure 9) investigate the role of MOP and FOP in induction of tumour activity, the results showed unexpectedly that male mice which were immunized with WBs and WBv serum and saliva of female Wives in group B showed growth of small dark red coloured nodules near the exterior aspect of the mice's neck and flank areas. These nodules were around $0.2 \mathrm{~mm}$ in diameter with a height of 0.1 to $0.2 \mathrm{~mm}$. The male

\begin{tabular}{|c|c|c|c|c|c|c|c|c|c|c|}
\hline $1 / 10$ & - & - & c & C & - & c & - & - & • & 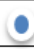 \\
\hline $1 / 20$ & - & - & - & $\bullet$ & - & $\bullet$ & - & - & $\bullet$ & 1 \\
\hline $1 / 40$ & 0 & 0 & c & $\bullet$ & - & 0 & c & 0 & 0 & 0 \\
\hline $1 / 80$ 랄 & 0 & 0 & c & $\bullet$ & 0 & 0 & 0 & 0 & 0 & 0 \\
\hline
\end{tabular}

Figure 7: The matching process results between $T_{2}$ as female oncogene peptide versus $T_{2}$ dilution of anti-Female oncogene antibodies in all females affected with breast cancer in group $A$, the first male Husband the intensity of blue colour in examined coated wells started to grow in the first two dilutions of $T_{1}$, four females showed growing of the blue colour with dilution 1/40 $T_{1}$ and only two females showed this blue colour growing in all dilutions of $T_{1}$.

AMOP T1 as first serum dilution $1 / 10$ of all females in group B

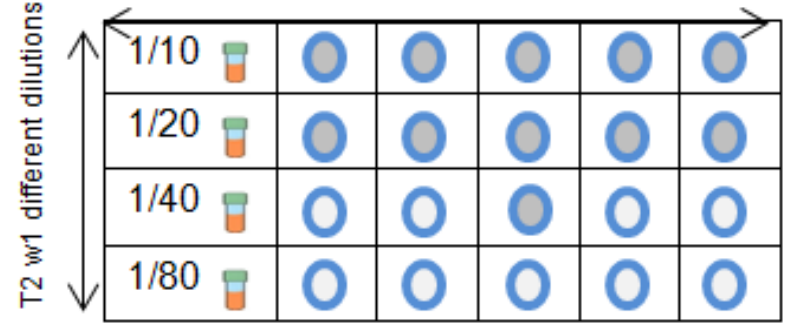

Figure 8: Matching the T1 dilution of each male affected for prostate cancer in group $B$ versus the different dilutions of $T 2$ for the first female Wives in the same group. The intensity of blue colour in examined coated well started to grow in the first two dilutions of T1 dilution of anti-Male oncogene peptide in al males affected for prostate cancer, and only one male showed this blue colour growing with $1 / 40$ of $\mathrm{T} 1$ dilution. 


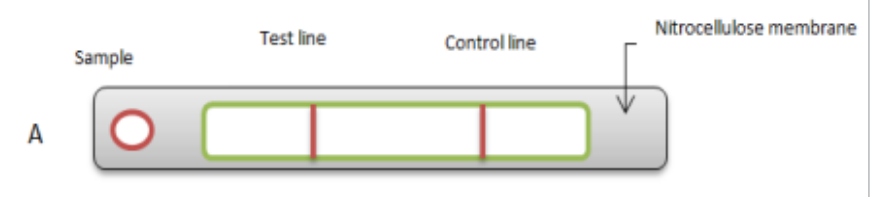

B

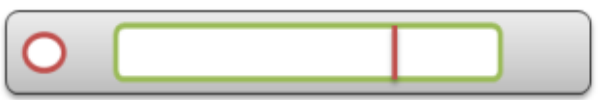

Figure 9: The strips which were used as a new marker for detection of prostate and breast cancer, where $A$ showed the positive result while $B$ showed negative result

mice showed signs of loss in weight and appetite. On the other hand, the injection of $\mathrm{MBs}$ and $\mathrm{MBv}$ as serum and saliva samples of males affected with prostate cancer in group B did not show any changes in their habits, weight or appetite and no abnormal cellular growth. Female mice which were immunized with HAs and HAv serum and saliva of male Husbands in group A showed growth of small reddish coloured nodules near the anterior belly. These growths were around $0.3 \mathrm{~mm}$ in diameter with a height of 0.4 to $0.5 \mathrm{~mm}$. The female mice showed signs of weight gain, excessive salivary secretion, and redness of the right eye, enlargement in the neck and hyper growth in mammary glands. Moreover, the injection of FAs and FAv as serum and saliva samples of females affected with breast cancer in group A did not show any changes in their habits, weight or appetite and no abnormal cellular growth. The male and female mice that were injected with serum and saliva samples of males and females of control groups did not show any remarkable signs. These results indicate that immunization of the female mice with serum and saliva of male Husband leads to enhancement of tumour growth, which means that the male Husband's serum or saliva contains an oncogene peptide that can stimulate the tumour growth, like the action of Husband's male oncogene in enhancement of the growth of breast cancer in females of group A. The same effect happened for male mice when we injected them with the serum and saliva of female Wives in group B. The female Wives proved that they contain female oncogene peptide that can stimulate the prostate cancer in their husbands of group $\mathrm{B}$ and tumour nodular growth in male mice. This observation proved the presence of male oncogene peptide in serum and saliva samples of male Husbands in group A and female oncogene peptide in serum and saliva of female Wives in group B.

Exploring the screening markers for detection of breast cancer and prostate cancer for all tested subjects revealed that among all known patients previously diagnosed with breast cancer by mammogram, breast ultrasound and tumour markers, the test area in the strip test showed positive reaction for all the examined ones and only two females of unknown 7 suspected patients showed positive reaction, and of the three suspected males two of them showed slightly positive reaction in the test area and the last one showed negative result. The data obtained with this screening tool carried promising data, so that we can consider this as a novel tumour marker for the future.

\section{Discussion}

Our novel study of breast cancer and prostate cancer revealed that in many of the cancerous cases affecting females as breast and men as prostate cancers, the masculine and feminine antigens play the main role in their display through a relation between the male and female like conjugal relations, as by being together over long periods, each of them plays the transmitter and receiver at the same time. Our postulation depends mainly on finding a correlative relation in conjugal relations, where one of them is affected by a cancerous case, whether it is a male affected by prostate cancer or a female affected by breast cancer. This reviled the existence of a common relation in the blood, linking them only, not others, where one of them represents an antigen to the other and the second bears the antagonist to this antigen. So that, if the female is affected, the male launches signs received by the eye or the ear, which induces in course of time a cancerous growth in one of them. Finally we had to prove that Affected females (Wives) who have breast cancer in their sexual organ have unknown antibody and their males (Husbands) who are not affected have unknown antigen, while affected males (Husbands) with prostate cancer in their sexual organs have unknown antibody and their females (Wives) who are not affected have antigen. In a pilot study for numerous cases of men and women affected really by noxious breast and prostate cancers and their partners, we detected antibodies and antigens in female and male affected with cancer of sexual organ. The results obtained from these experimental trails, finally introduced a newly discovered peptides as Male oncogene peptide and antibodies which derived from samples of affected women for breast cancer as well as male for prostate cancer and when we injected it into Female and male lab mice, we found that the discovered oncogene peptides can induce the tumour activity and these antibodies have potential inhibiting effect for growing of cancerous activity within the tested mice. According to these results we can raise our possibility for producing and developing prophylactic and therapeutic vaccine for two of the most dangerous cancer According to these results, The outcome data when we used the new screening markers for detection of breast cancer and prostate cancer for all tested subjects revealed that among all known patients previously diagnosed with breast cancer by mammogram, breast ultrasound and tumour markers, the test area in the strip test showed positive reaction for all the examined ones and only two females of unknown 7 suspected patients showed positive reaction, and the three suspected males two of them showed slightly positive reaction in the test area and the last one showed negative result. The data obtained with this screening tool carried promising data, so that we can consider this as a novel tumour marker for the future.

\section{Conclusion}

This study explains a probable new cause behind the triggers for breast and prostate cancer, and also introduces a new tumour marker indicator that depends on finding a new undiscovered oncogene peptide and its specific antibodies in serum and saliva of women liable for breast cancer and their husbands, as well as men susceptible to prostate cancer and their wives. Also it introduces a new concept that enables us to design a new vaccine for both types of cancer.

\section{Acknowledgement}

My deep appreciation to all volunteers for their participation, I also offer specia thanks to Dr. Mohamed Sherif for the thought-provoking discussions and his critical review of the manuscript.

\section{References}

1. Moreno-Smith M, Lutgendorf SK, Sood AK (2010) Impact of stress on cancer metastasis. Future Oncol 6: 1863-1881.

2. Andersen BL, Kiecolt-Glaser JK, Glaser R (1994) Biobehavioural model of cancer stress and disease course. Am Psychol 49: 389-404.

3. Antoni MH, Lutgendorf SK, Cole SW, Dhabhar FS, Sephton SE, et al. (2006) The influence of bio-behavioural factors on tumour biology: pathways and mechanisms. Nat Rev Cancer 6: 240-248.

4. 4. Anglian Breast Cancer Study Group (2000) Prevalence and penetrance of BRCA1 and BRCA2 mutations in a population- based series of breast cancer cases. Br J Cancer 83: 1301-1308. 
Citation: Hesen SS, Sherif N (2018) Novel Revolution in Diagnosis and Therapy of Breast and prostate Cancer. J Cancer Sci Ther 10: 110-117. doi: 10.4172/1948-5956.1000527

5. Gion M, Mione R, Leon AE, Dittadi R (1999) Comparison of the diagnostic accuracy of CA27.29 and CA15.3 in primary breast cancer. Clin Chem 45 : $630-637$.

6. Antoniou A, Pharoah PD, Narod S, Risch HA, Eyfjord JE, et al. (2003) Average risks of breast and ovarian cancer associated with BRCA1 or BRCA2 mutations detected in case series unselected for family history: A combined analysis of 22 studies. Am J Hum Genet 72: 1117-1130.

7. Albertsen PC, Hanley JA, Fine J (2005) 20-year outcomes following conservative management of clinically localized prostate cancer. JAMA 293: 2095-2101.

8. Feigelson HS, Ross RK, Yu MC, Coetzee GA, Reichardt JK, et al. (1996) Genetic susceptibility to cancer from exogenous and endogenous exposure. J Cell Biochem 25: 15-22.

9. Henderson BE, Ross RK, Pike MC, Casagrande JT (1982) Endogenous hormones as a major factor in human cancer. Cancer Res 24: 3232-3239.

10. Catalona WJ, Richie JP, Ahmann FR, Hudson MA, Scardino PF, et al. (1994)
Comparison of digital rectal examination and serum prostate specific antigen in the early detection of prostate cancer: results of a multicenter clinical trial of 6,630 men. J Urol 151: 1283-1290.

11. Fletcher RH (1996) Carcinoembryonic antigen. Ann Intern Med 104: 66-73.

12. (1996) Clinical practice guidelines for the use of tumour markers in breast and colorectal cancer. Adopted on May 17, 1996, by the American Society of Clinical Oncology. J Clin Oncol 14: 2843-2877.

13. Ugelstad J, Olsvik O, Schmid R, Berge A, Funderud S (1993) Nevertheless, the importance of Nustad, in: T.T. Ngo (Eds.), Molecular Interactions in Bioother specific affinity ligands interacting with SPE- separations, Plenum Press, New York pp: 229.

14. Prestvik WS, Berge A, Mork PC, Stenstad PM, Zborowskidrates M (1997) Antigens or phages will be increasing. Ugelstad, In: Magnetic separation techniques are compatible scientific and clinical applications of magnetic carriers. Hafeli U, Schutt W, Teller J, Zborowski M. (Eds.), Plenum Press, New York, London, UK. p: 11. 